\title{
Nuevas perspectivas sobre la materia médica: los vínculos históricos entre la geología y la medicina
}

\author{
New perspectives on the materia medica: \\ the historical links between geology and medicine
}

\author{
Irina Podgorny \\ Investigadora, Conicet - Archivo Histórico del Museo de La Plata. \\ ipodgo@isis.unlp.edu.ar
}

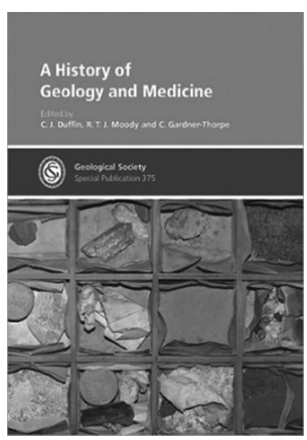

DUFFIN, C.J.; MOODY, R.T.J.; GARDNER-THORPE, C. (Ed.). A history of geology and medicine. London: Geological Society. 2013.512p.
T a geología médica, una disciplina que surgió en los últimos

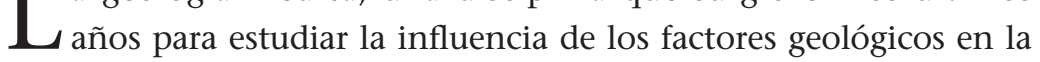
distribución geográfica de los problemas sanitarios, ha reflotado la vieja relación entre medicina y geología. Aunque separadas en el siglo XX, estas dos ramas del saber aplicado presentan innumerables temas en común tal como el estudio de la deficiencia de minerales o los efectos del polvo volcánico en la salud humana y veterinaria. Sin embargo, los investigadores del siglo XXI, lejos de agitar la novedad del asunto, prefieren anclar este enfoque en las tradiciones terapéuticas del mundo antiguo y de la modernidad temprana. No están equivocados: durante siglos el mundo natural, es decir, los reinos animal, vegetal y mineral, fueron concebidos como un repositorio de remedios. Como es bien sabido, hasta el siglo XVIII, la historia natural y la medicina caminaron de la mano. "La Tierra es la farmacia de Dios", decía Oswald Croll (1563-1609), un médico alquimista seguidor de Paracelso.

Esta Historia de la geología y la medicina, resultado de un coloquio organizado en noviembre de 2011 por el Grupo de Historia de la Geología, afiliado a la Geological Society de Londres, se ocupa, precisamente, de esos vínculos históricos. ${ }^{1}$ En ese sentido, representa un primer paso en aras de sistematizar un tema de investigación prometedor, hasta ahora poco explorado por los historiadores. En efecto, aunque los herbolarios y la etnobotánica y, en menor medida, la materia médica animal, han sido analizados con detalle, la materia médica mineral y los "geofármacos" permanecen como un tema pendiente.

Christopher Duffin, uno de los editores del libro, recuerda en la introducción que un experto en la historia del uso de fósiles y rocas como remedios, el médico y farmacéutico alemán Hermann Georg Fühner (1871-1944), quizás haya sido el primero en usar y acuñar la palabra "litoterapia" para referirse al uso de las piedras preciosas en la medicina. 
En Lithotherapie, historische studien über die medizinische Verwendung der Edelsteine, su tesis doctoral de 1902, Fühnen trabajó con los lapidarios y la bibliografía a su alcance para analizar este asunto entre los pueblos "primitivos" y antiguos, incluyendo las medicinas de la China, India, Babilonia, Egipto, Grecia, Roma y las autoridades latinas y medievales. Duffin, correctamente, recuerda que este trabajo quedó como una iniciativa aislada, luego aprovechada por los movimientos "New Age" que creen encontrar allí una legitimación a sus ideas sobre la energía que emanaría de las piedras (p.1). El interés por los poderes de determinadas gemas o el uso de las piedras como talismanes, sin dudas, debe rastrearse en estas fuentes.

Duffin, como antes Fühner, destaca la importancia de los minerales en la antigüedad clásica, en particular en la obra del médico griego Pedacio Dioscórides Anazarbeo (ca. 40-90), cirujano imperial de Nerón y de las legiones romanas, autor de la Materia médica (64). Esta obra monumental, dedicada sobre todo a las sustancias vegetales, incluía el uso terapéutico de las piedras metálicas, las tierras y las aguas. Como es bien sabido, la Materia médica fue la referencia ineludible de la medicina del milenio y medio que siguió a su escritura. Lo mismo ocurre con la Historia natural (77) de Gayo Plinio Segundo (conocido como Plinio El Viejo, 23-79), compilación contemporánea de la Materia médica que recogió el saber médico erudito y folclórico de la época. Ambos trabajos, combinados con los de los autores árabes y los lapidarios y bestiarios medievales, representan las fuentes donde rastrear las tradiciones más diversas respecto del uso y la aplicación médica de materiales que hoy se definen como geológicos.

El libro reúne 29 trabajos, presentados en el coloquio 2011, bajo dos temas principales: la historia del uso terapéutico de los materiales geológicos y los aportes de aquellos individuos que trabajaron en ambas disciplinas. Los capítulos tratan una extensa variedad de temas, las geografías tratadas en el encuentro y en la obra, sin embargo, se centran en el llamado Viejo Mundo y, especialmente, en Europa.

Los distintos capítulos, muy bien ilustrados, ponen al alcance del lector un repaso exhaustivo de cómo las piedras, las tierras, las aguas y los fósiles, en su sentido contemporáneo, aparecen tratados en las obras de los autores antiguos, árabes y medievales. Mientras otros trabajos se abocan a temas de la medicina popular y a algunos materiales específicos (bezoares, "Sunday stones", gemas y fósiles), aproximadamente la mitad del libro se dedica a la confluencia entre medicina y geología en la obra de ciertos individuos, entre los que se cuentan y mencionan Charles Darwin, Ole Worm, Nicolás Steno y James Parkinson, este último mejor conocido por la enfermedad que lleva su nombre. Como se señala, varios de los fundadores de la Geological Society eran médicos y la práctica de la geología del siglo XIX no puede desentenderse de este hecho, ya sea por el tipo de matriz que esto implica para ordenar los datos recogidos en el campo, ya sea por la formación de los médicos en relación a la materia médica y el mundo natural.

Ante la pérdida de eficacia de los antibióticos modernos, algunos de los materiales tratados en el libro están siendo re-estudiados de manera interdisciplinaria como alternativa farmacéutica, un tema que se desarrolló con mayor detalle en el segundo encuentro "Medicine and Geology" del año 2014. Entre esos materiales, sobresale la terra sigillata o tierra sellada, esa arcilla medicinal procedente de la isla de Lemnos en el mar Egeo, comercializada desde la antigüedad a gran escala por griegos y turcos y de amplia circulación en el Renacimiento, 
cuando se la usaba como antídoto y como tratamiento contra distintas fiebres e infecciones. ${ }^{2}$ El trabajo conjunto de arqueólogos, historiadores y bioquímicos ha determinado las distintas fuentes de estos materiales, habiéndose experimentado y comprobado el efecto antiséptico de algunos de ellos. De allí a la producción de un medicamento, queda un largo trecho que, sin dudas, abre innumerables preguntas a resolver e investigar. Así, lejos del esoterismo, estamos frente a un tema de indudable relevancia, donde el pasado se vincula al futuro y, quizás, a la resolución de problemas sanitarios. Por eso, este volumen, más allá de la diversidad del enfoque de los autores, es un hecho que merece celebrarse.

\section{NOTAS}

${ }^{1}$ El índice del libro está disponible en el siguiente enlace: http://ebooks.geoscienceworld.org/content/ahistory-of-geology-and-medicine.

2 Para saber más sobre las tierras de Lemnos, ver: http://www.gla.ac.uk/schools/humanities/research/ archaeologyresearch/projects/industrialminerals/samoslemnos/lemnianearth/; y http://www.potingair.com/ LEandearthsofAegean.htm. 